\title{
Non-English majors' employment of autonomous English lexical learning strategies
}

\author{
Tran Quoc Thao ${ }^{1 *}$ \\ ${ }^{1}$ Ho Chi Minh City University of Technology (HUTECH), Vietnam \\ *Corresponding author: tq.thao@ hutech.edu.vn, tranquocthaobmtc@yahoo.com
}

ARTICLE INFO

DOI: $10.46223 / \mathrm{HCMCOUJS}$. soci.en.10.1.540.2020

Received: June $9^{\text {th }}, 2020$

Revised: June $17^{\text {th }}, 2020$

Accepted: June $29^{\text {th }}, 2020$

Keywords:

autonomy, English, nonEnglish majors, strategy, lexical language strategy
ABSTRACT
The lexicon is one of the most core elements in a language system, so acquiring/learning it is a must-do job for ESL/EFL learners. Nevertheless, whether ESL/EFL learners can employ English lexical learning strategies (LLS) autonomously or not has concerned researchers and educators in different contexts. This study, therefore, endeavors to explore the use of autonomous English LLS by non-English majors at a technical Ho Chi Minh City-based university in Vietnam. It involved 200 students in answering a closed-ended questionnaire and ten students in semistructured interviews. The results revealed that research participants sometimes utilized LLS autonomously in English language learning. Among five groups of autonomous English LLS, participants sometimes tended to use more determination strategies than other groups of social, cognitive, and metacognitive strategies and memory strategies. Additionally, the results showed that females utilized English LLS more autonomously than males. The findings imply that technical students, especially male students, seemed not to focus much on English LLS.

\section{Introduction}

Researchers (e.g., Benson, 2001; Duong, 2014; Duong \& Seepho, 2013; Gremmo \& Riley, 1995; T. Q. Tran \& L. C. H. Nguyen, 2020; T. Q. Tran \& T. G. Nguyen, 2017; Tran \& Vo, 2019) have paid much attention to the development of learner autonomy as an alternative approach in education in general and in language learning in particular. Hence, ESL/EFL teachers in different contexts are aware of the importance of learner autonomy (Cotterall, 2000), and believe that developing learner autonomy to ESL/EFL learners can be effective in assisting learners to learn independently (O’Malley \& Chamot, 1990).

It is agreed that the lexicon is a vital factor in English language teaching and learning. If one does not have enough lexicons to express his ideas in communication, one may not succeed in conversations (McCarthy, 1992). Likewise, the lexicon is the core component in a language system, so mastering lexicon can help learners enhance their language skills (Richards \& Renandya, 2002). Hence, a learning lexicon is extremely essential because it can help learners to enhance their English language skills effectively. Accordingly, learners should be introduced to lexical learning strategies (LLS) and encouraged to undertake independent learning both inside and outside the classroom.

In Vietnam, the English language is one of the compulsory subjects to be learned at different levels of education. It is observed, nonetheless, that while some students are motivated 
and eager to delve themselves into learning English at different times, many are still struggling in learning it effectively. This can be derived from their ability to learn independently (e.g., Duong, 2014; Duong \& Seepho, 2013; Nguyen, 2013; Tran \& Duong, 2018). It is further noticed that a large proportion of students cannot use English well although they have learned English for years. One of the possible reasons for that is they lack lexicons. They learn English lexicons by memorizing a long list of lexicons provided by their teachers (Nguyen, 2013). This study, therefore, attempts to explore the use of autonomous English LLS by technical non-English majors at a Ho Chi Minh City based higher institution. The following research questions are formed:

1. How do non-English majors at a higher institution use English LLS autonomously?

2. Do male students use English LLS differently from their female counterparts? If yes, how?

\section{Literature review}

LLS are variously defined. Intaraprasert (2005) has defined that LLS are a set of techniques to broaden lexical knowledge. Similarly, Naveh, Kafipour, and Scoltani (2011) have defined that LLS are strategies used to learn lexicons independently. Within the scope of this study, LLS are understood as techniques utilized by language learners to learn lexicons easily.

LLS are extremely vital in learning a language as learners can get various benefits from LLS. Nation (2001) believes that learners can grasp a great number of lexicons by using LLS. In addition, when learners are aware of LLS, they can deal with unknown words effectively. Besides, autonomous learners are seen to learn lexicons effectively (Gu \& Johnson, 1996). As learners cannot learn all lexicons provided in language classes, they have to look for other useful ways to master language lexicons effectively.

Different classifications of LLS have been found in the body of literature. Schmitt (1997) has grouped LLS is into two main categories, viz. discovery strategies and consolidating strategies. The former consists of determination and social strategies while the latter comprises social, memory, cognitive, and metacognitive strategies. Both groups by Schmitt (1997) include social strategies as they can be used for various purposes. Meanwhile, Intaraprasert (2005) classifies LLS into three main categories, namely Strategies to Discover the Meaning of New Vocabulary Items, Strategies to Retain the Knowledge of Newly Learned Vocabulary and Strategies to Expand the Knowledge of Vocabulary Items. Autonomous learners tend to employ different types of LLS (T. Q. Tran \& T.G. Nguyen, 2017) which can fall in Schmitt's (1997) taxonomy of LLS or Intaraprasert's (2005) classification of LLS. For this study, the Schmitt's (1997) taxonomy of LLS is mainly relied on for theoretical foundation as it is comprehensive and suitable for the aims of this study.

Prior studies have indicated that different aspects of LLS have been explored in different contexts. Significantly, Khalifa and Shabdin (2016) studied the impact of LLS on secondary school students' learner autonomy development in Libya. Pre-test/post-test and logbooks were used to collect data. The results showed that experimental group participants outperformed in autonomous lexical learning. Another study was conducted by Sedighi and Tamjid (2016) who explored the correlation between LLS and learner autonomy of Iranian EFL learners. This study involved 82 sophomore and junior students at Tabriz Azad University in answering two sets of questionnaires. It was found that students' use of LLS was positively correlated with their autonomy. Recently, Besthia (2018) investigated Indonesian university students' use of LLS. 74 students were answering the 40-item questionnaire. The findings indicated that students used Determination Strategies the most and Social Strategies the least. In the context of Vietnam, several studies (e.g., 
Le, 2018; Luu, 2001; Pham, 2010; Trinh \& Trinh, 2019) relevant to LLS have been conducted. Pham (2010) investigated first-year students' LLS use a university in Hanoi. There were 421 students from different majors answering the questionnaire. It was found that participants used LLS at a medium level, and students from different majors did not use LLS significantly differently. Le (2018) researched on students' use of academic LLS at a university. There were 132 students taking part in answering a questionnaire. The results showed that participants tended to employ online dictionary and applications more often than cognitive strategies. Trinh and Trinh (2019) did a study on LLS used by the English majored students at Tra Vinh University. It involved 40 third-year students in answering the questionnaire. The results indicated that participants used strategies relevant to autonomy and dictionary most frequently while they employed guessing and social strategies the least. In brief, it is noticed that different studies have examined the LLS use in different contexts; nonetheless, the focus of autonomous use of LLS is not much explored yet. Therefore, this study is carried to explore the use of autonomous English LLS by non-English majors at a technical university in Ho Chi Minh City.

\section{Research methodology}

\subsection{Research context and participants}

This mixed-methods study was carried out at a higher institution in Ho Chi Minh City, which is mainly a technical university. Students at this university have to learn different courses of English within the first two years in their tertiary program, and the total number of credits of English courses they have to take is 18 .

Two-hundred second-year students were purposively sampled from different majors to take part in this study. The number of 88 male students accounts for $44 \%$ ( 88 participants) while that of female students is responsible for $56 \%$ (122 participants). Nearly $70 \%$ (137) of participants allocated less than one hour each day to self-studying English lexicons, but only 2\% (4) of participants spent two hours on lexical learning daily. In addition, 34 participants (17\%) and 25 participants $(12.5 \%)$ spared about one hour and from one to two hours daily respectively to learn English lexicons. Ten students from 200 participants were purposively invited for semi-structured interviews.

\subsection{Research instruments}

The questionnaire and semi-structured interviews were employed for data collection. The closed-ended questionnaire which was adapted from Schmitt's (2010) study consists of two parts: Part A asking for respondent's background information; Part B consisting of 34 items grouped into the five strategies: determination strategies (5 items), social strategies (5 items), memory strategies (10 items), cognitive strategies ( 7 items) and metacognitive strategies (6 items). The five-point Likert-scale (from $1=$ never to $5=$ always) was employed. The questionnaire was translated into Vietnamese to make sure that respondents did not meet any language difficulty in responding to the questionnaire. Regarding the reliability of the questionnaire, Cronbach's alpha was .82 for the whole questionnaire. This means that the questionnaire was very reliable.

The semi-structured interview was employed to get in-depth information and cross-check the data gained from the questionnaire. It includes five main questions which were designed based on the research aims. All the interview questions were also translated into students' mother tongue so that interviewees could express their answers fully.

\subsection{Procedures for data collection and analysis}

Concerning data collection, after the questionnaire and interview had been piloted, two 
hundred copies of questionnaires were administered to students in person. Respondents spent around 20 minutes on finishing the questionnaire. Then, ten students were invited for a face to face interviews. Each interview took place around 20 minutes. All interviews were recorded for later transcription.

Regarding data analysis, there were two types of data: quantitative data and qualitative data. The former was analyzed using SPSS in terms of mean score, standard deviation, and Independent T-test, while the latter was analyzed utilizing the content analysis approach. The interval scores of the five-point Likert scale were interpreted as $1.00-1.80$ : Never; $1.81-2.60$ : Seldom; 2.61 - 3.40: Sometimes; 3.41 - 4.20: Often; 4.21 - 5.00: Always. The interviewees were coded as S1, S2 to S10.

\section{Results and discussion}

\subsection{Results}

\subsubsection{Non-English majors' use of autonomous English LLS}

It is seen from Table 1 that the overall mean score of non-English majors' use of autonomous English LLS is 2.83. To put it another way, the participants sometimes employed English LLS Among five groups of English LLS, Determination strategies was recognized to be the most frequently used $(\mathrm{G} 1, \mathrm{M}=3.14, \mathrm{~S} . \mathrm{D} .=.64)$, followed by Metacognitive strategies $(\mathrm{G} 5, \mathrm{M}=2.82$, S.D. $=.72)$, Social strategies $(\mathrm{G} 2, \mathrm{M}=2.80$, S.D. $=.63)$ and Cognitive strategies $(\mathrm{G} 4, \mathrm{M}=2.69$, S.D. =.62). Memory strategies was the least used English LLS (G3, M = 2.67, S.D. = .60).

\section{Table 1}

Non-English majors' use of autonomous English LLS

\begin{tabular}{|c|l|c|c|}
\hline \multirow{2}{*}{ No. } & & \multicolumn{2}{|c|}{ N=200 } \\
\cline { 3 - 4 } & & M & SD \\
\hline G1 & Determination strategies & 3.14 & .64 \\
\hline G2 & Social strategies & 2.80 & .63 \\
\hline G3 & Memory strategies & 2.67 & .60 \\
\hline G4 & Cognitive strategies & 2.69 & .62 \\
\hline G5 & Metacognitive strategies & 2.82 & .72 \\
\hline & Overall & $\mathbf{2 . 8 3}$ & $\mathbf{. 4 4}$ \\
\hline
\end{tabular}

Note: M: Mean; SD: Standard Deviation

Source: Data analysis result of the research

Specifically, Table 2 indicates that participants often used a bilingual dictionary for learning lexicons (Item $4, \mathrm{M}=4.55, \mathrm{SD}=.75$ ). In addition, they sometimes guessed the lexical meanings by using available pictures and objects (Item 3, M=3.06, $\mathrm{SD}=1.06$ ), or by analyzing the structure of the lexicons (Item $1, \mathrm{M}=2.82, \mathrm{SD}=1.19$ ), or by guessing the lexical meanings from contexts (Item $2, \mathrm{M}=2.81, \mathrm{SD}=1.17$ ). However, monolingual dictionary was rarely exploited (Item $5, \mathrm{M}=2.46, \mathrm{SD}=1.10$ ). This means that participants sometimes utilized determination strategies to learn lexicons. 


\section{Table 2}

Non-English majors' use of autonomous English LLS in terms of Determination strategies

\begin{tabular}{|c|l|c|c|}
\hline \multirow{2}{*}{ No. } & \multicolumn{1}{|c|}{ Determination strategies } & \multicolumn{2}{|c|}{ N=200 } \\
\cline { 3 - 4 } & \multicolumn{1}{|c|}{ M } & SD \\
\hline 1 & $\begin{array}{l}\text { I guess the lexical meanings by analyzing the structure of words } \\
\text { (e.g., prefixes, roots, or suffixes). }\end{array}$ & 2.82 & 1.19 \\
\hline 2 & I guess lexical meanings from contexts. & 2.81 & 1.17 \\
\hline 3 & $\begin{array}{l}\text { I guess the lexical meanings from contexts through available pictures } \\
\text { and objects. }\end{array}$ & 3.06 & 1.21 \\
\hline 4 & I use a bilingual dictionary to find out the lexical meanings. & 4.55 & .75 \\
\hline 5 & I use a monolingual dictionary to check the lexical meanings. & 2.46 & 1.10 \\
\hline
\end{tabular}

Note: M: Mean; SD: Standard Deviation

Source: Data analysis result of the research

The qualitative findings supported the quantitative ones. Participants preferred determination strategies to learn lexicons. For example:

I am not well aware of LLS, but I like using a dictionary to look up the lexical meanings. (S2)

I often use a dictionary in my cellphone to look up the meanings and pronunciation of new words. (S4)

Results in Table 3 indicate that the participants often asked teachers for L1 translation (Item $6, \mathrm{M}=3.98, \mathrm{SD}=1.15$ ) and asked classmates for meaning (Item $8, \mathrm{M}=3.67, \mathrm{SD}=1.17$ ). However, they seldom asked the teacher for paraphrases or synonyms (Item 7, M =2.31, SD =1.15), studied lexical meanings through group work (Item 9, $\mathrm{M}=2.06, \mathrm{SD}=.96$ ) and interacted with native speakers to construct lexical meanings (Item 10, $\mathrm{M}=1.99, \mathrm{SD}=.95$ ).

\section{Table 3}

Non-English majors' use of autonomous English LLS in terms of Social strategy

\begin{tabular}{|c|l|c|c|}
\hline \multirow{2}{*}{ No. } & \multicolumn{1}{|c|}{ Social strategy } & \multicolumn{2}{c|}{ N=200 } \\
\cline { 3 - 4 } & & M & SD \\
\hline 6 & I ask teachers for L1 translation. & 3.98 & 1.15 \\
\hline 7 & I ask teachers for paraphrases or synonyms. & 2.31 & 1.15 \\
\hline 8 & I ask classmates for meaning. & 3.67 & 1.17 \\
\hline 9 & I study lexical meanings through group work. & 2.06 & .96 \\
\hline 10 & I interact with native speakers. & 1.99 & .95 \\
\hline
\end{tabular}

Note: M: Mean; SD: Standard Deviation

Source: Data analysis result of the research 
Similar to the quantitative results, the qualitative findings revealed that participants used social strategies in learning lexicons.

When I am not sure of the meaning of new words, I ask my friends, English teachers and even foreign friends. (S1)

I often talk to my classmates to check the meaning of new words because it is more convenient for me. (S6)

Results in Table 4 present that participants often "read lexicons aloud when studying them" (Item 19, M = 3.58, SD =1.18), but they sometimes "use physical action in lexical learning" (Item $20, \mathrm{M}=3.20, \mathrm{SD}=1.20$ ), "link newly-learned lexicons to previous personal experience" Item 11, $\mathrm{M}=3.14$, SD = .98), "connect newly-learned lexicons to previous-learned ones" (Item 12, $\mathrm{M}=$ 2.91 , S.D. =1.47), "associate the lexicons in their synonyms or antonyms" (Item 13, M = 2.64, SD $=1.06$ ) and "group lexicons together to study them" (Item $16, \mathrm{M}=2.61, \mathrm{SD}=1.18$ ). In addition, participants seldom "study the spelling of a lexicon" (Item 18, M = 2.41, SD = 1.19), "employ the keyword method to study lexicons" (Item $17, \mathrm{M}=2.22, \mathrm{SD}=1.11$ ), "employ semantic maps to learn lexicons" (Item $14, \mathrm{M}=2.02, \mathrm{SD}=.88$ ) and "connect pictures, flashcards or real objects with lexicons" (Item 15, M=1.98, SD = 1.02).

\section{Table 4}

Non-English majors' use of autonomous English LLS in terms of Memory strategies

\begin{tabular}{|c|l|c|c|}
\hline \multirow{2}{*}{ No. } & \multicolumn{1}{|c|}{ Memory strategies } & \multicolumn{2}{|c|}{ N=200 } \\
\cline { 3 - 4 } & & M & SD \\
\hline 11 & I link newly-learned lexicons to previous personal experience. & 3.14 & .98 \\
\hline 12 & I connect newly-learned lexicons to previous-learned ones. & 2.91 & 1.47 \\
\hline 13 & I associate the lexicons in their synonyms or antonyms. & 2.64 & 1.06 \\
\hline 14 & I employ semantic maps to learn lexicons. & 2.02 & .88 \\
\hline 15 & I connect pictures, flashcards, or real objects with lexicons. & 1.98 & 1.02 \\
\hline 16 & I group lexicons to study them. & 2.61 & 1.18 \\
\hline 17 & I employ the keyword method to study lexicons. & 2.22 & 1.11 \\
\hline 18 & I study the spelling of a lexicon. & 2.41 & 1.19 \\
\hline 19 & I read lexicons aloud when studying them. & 3.58 & 1.18 \\
\hline 20 & I use physical action in lexical learning. & 3.20 & 1.20 \\
\hline
\end{tabular}

Note: M: Mean; SD: Standard Deviation

Source: Data analysis result of the research

As seen from Table 5, participants sometimes "highlight lexicons [they] want to learn" (Item $27, \mathrm{M}=3.61, \mathrm{SD}=1.40$ ), "repeat the lexicon with its meaning many times" (Item $22, \mathrm{M}=$ $3.11, \mathrm{SD}=1.40$ ), "keep a lexicon notebook" (Item 21, M = 2.85, SD = 1.18) and write the lexicons with their meaning many times (Item $23, \mathrm{M}=2.74, \mathrm{SD}=1.07$ ). Nevertheless, they seldom "take notes in class" (Item $24, \mathrm{M}=2.35, \mathrm{SD}=1.26$ ), "write lexicons with meanings on stickers" (Item $25, \mathrm{M}=2.34, \mathrm{SD}=1.22$ ) and "write lexicons on the board in [their] room" (Item 26, $\mathrm{M}=1.84$, 
$\mathrm{SD}=.99)$

\section{Table 5}

Non-English majors' use of autonomous English LLS in terms of Cognitive strategy

\begin{tabular}{|c|l|c|c|}
\hline \multirow{2}{*}{ No. } & \multicolumn{1}{|c|}{ Cognitive strategies } & \multicolumn{1}{|c|}{ N=200 } \\
\cline { 2 - 4 } & \multicolumn{1}{|c|}{ M } & SD \\
\hline 21 & I keep a vocabulary notebook. & 2.85 & 1.18 \\
\hline 22 & I say the word with its meaning repeatedly. & 3.11 & 1.40 \\
\hline 23 & I write the word with its meaning repeatedly. & 2.74 & 1.07 \\
\hline 24 & I take notes in class. & 2.35 & 1.26 \\
\hline 25 & $\begin{array}{l}\text { I write vocabulary items with meanings on papers and stick them on } \\
\text { physical objects. }\end{array}$ & 2.34 & 1.22 \\
\hline 26 & $\begin{array}{l}\text { I write vocabulary items with meanings on papers and stick them on } \\
\text { the wall in my room. }\end{array}$ & 1.84 & .99 \\
\hline 27 & I highlight new words. & 3.61 & 1.40 \\
\hline
\end{tabular}

Note: M: Mean; SD: Standard Deviation

Source: Data analysis result of the research

Findings from the qualitative data showed that interviewees employed this group of strategies in lexical learning.

I highlight lexicons I want to learn because this way can help me learn new words quickly. (S4)

I try to repeat new words or write them many times so that I can remember them well. (S7)

It can be seen in Table 6, respondents often learnt lexicons through English songs (Item $28, \mathrm{M}=4.19, \mathrm{SD}=1.06$ ), but they sometimes learnt lexicons from "playing English games" (Item $31, \mathrm{M}=3.38, \mathrm{SD}=1.19$ ), "websites for lexical learning" (Item 34, M = 2.71, SD = 1.26), "doing English lexical tests" (Item 32, M = 2.52, SD = 1.14), and "reading English news online" (Item $30, \mathrm{M}=2.42, \mathrm{SD}=1.28$ ). Plus, they rarely learnt lexicons from "listening to English radio" (Item $33, \mathrm{M}=2.29, \mathrm{SD}=1.30$ ) and "watching English programs" (Item 29, $\mathrm{M}=2.25, \mathrm{SD}=1.32$ ).

\section{Table 6}

Non-English majors' use of use of autonomous English LLS in terms of Metacognitive strategies

\begin{tabular}{|c|l|c|c|}
\hline \multirow{2}{*}{ No. } & \multicolumn{1}{|c|}{ Metacognitive strategies } & \multicolumn{2}{|c|}{ N=200 } \\
\cline { 3 - 4 } & & M & SD \\
\hline 28 & I learn lexicons through English songs. & 4.19 & 1.06 \\
\hline 29 & I learn lexicons from watching English programs. & 2.25 & 1.32 \\
\hline 30 & I learn lexicons from reading English news online. & 2.42 & 1.28 \\
\hline 31 & I learn lexicons from playing English games. & 3.38 & 1.19 \\
\hline 32 & I learn lexicons from doing English lexical tests. & 2.52 & 1.14 \\
\hline 33 & I learn lexicons from listening to English radio. & 2.29 & 1.30 \\
\hline 34 & I learn lexicons from websites for lexical learning. & 2.71 & 1.26 \\
\hline
\end{tabular}


Source: Data analysis result of the research

Data gained from interviews showed that interviewees were interested in using metacognitive strategies to learn vocabulary. Some examples are as follows:

I love learning vocabulary by singing or listening to English songs as it is relaxing and enjoyable. (S1)

...I often read books or newspapers in English to learn new words. (S10)

\subsubsection{Differences in autonomous English LLS use in terms of gender}

Table 7 shows that a significant difference in autonomous English LLS use between male students and their female counterparts $(\mathrm{t}=-7.517 ; \mathrm{p}=.0000)$ was found. This implies that female students $(\mathrm{M}=2.99, \mathrm{SD}=.41)$ tended to use autonomous English LLS more frequently than their male counterpart $(\mathrm{M}=2.60, \mathrm{SD}=.36)$.

Regarding the groups of autonomous English LLS, it was noticed that there were differences in all five strategy groups between male and female students. The mean score of determination strategies $(\mathrm{M}=3.40, \mathrm{SD}=.42)$, social strategies $(\mathrm{M}=2.99, \mathrm{SD}=.57)$, memory strategies $(\mathrm{M}=2.99, \mathrm{SD}=.43)$, and metacognitive strategies $(\mathrm{M}=3.03, \mathrm{SD}=.73)$ for females was higher than that for $(\mathrm{M}=2.81, \mathrm{SD}=.71 ; \mathrm{M}=2.56, \mathrm{SD}=.63 ; \mathrm{M}=2.25, \mathrm{SD}=.51 ; \mathrm{M}=2.56$, $\mathrm{SD}=.61$ ) for males, respectively. Nevertheless, the mean score of cognitive strategies for females $(\mathrm{M}=2.57, \mathrm{SD}=.68)$ was lower than that of males $(\mathrm{M}=2.84, \mathrm{SD}=.49)$. This means that while determination, social, memory and metacognitive strategies were employed more frequently by female participants, cognitive strategies were used more frequently by male participants.

\section{Table 7}

Differences in autonomous English LLS use in terms of gender

\begin{tabular}{|l|c|c|c|c|}
\hline \multirow{2}{*}{\multicolumn{1}{c|}{ Variables }} & \multirow{2}{*}{ Sig. } & $\mathbf{t}$ & \multicolumn{2}{c|}{ M(SD) } \\
\cline { 4 - 5 } & $.000^{*}$ & -6.956 & $2.81(.71)$ & $3.40(.42)$ \\
\hline Determination strategies & $.000^{*}$ & -5.123 & $2.56(.63)$ & $2.99(57)$ \\
\hline Social strategies & $.000^{*}$ & -10.976 & $2.25(.51)$ & $2.99(.43)$ \\
\hline Memory strategies & $.002^{*}$ & 3.206 & $2.84(.49)$ & $2.57(.68)$ \\
\hline Cognitive strategies & $.000^{*}$ & -4.872 & $2.56(.61)$ & $3.03(.73)$ \\
\hline Metacognitive strategies & $.000^{*}$ & -7.157 & $2.60(.36)$ & $2.99(.41)$ \\
\hline Overall strategy use & & & & \\
\hline
\end{tabular}

Note: M: Mean; SD: Standard Deviation * $\mathrm{p}<0.01$

Source: Data analysis result of the research

\subsection{Discussion}

This study has revealed some remarkable findings in non-English majored students' use of autonomous English LLS. Overall, participants in this study did not employ autonomous English LLS very often to deal with lexicons. Some plausible reasons are as follows. The first reason can be that students may learn lexicons for doing exercises or tests. Secondly, they may not get used to using different strategies to boost their English lexical learning. The last reason can be due to time constraints in class. Teachers may not allocate adequate time to instructing their students to utilize various LLS. 
Participants in this study preferred determination strategies to learn lexicons. Specifically, it was found that participants employed a bilingual dictionary more frequently than utilizing a monolingual dictionary and guessing the lexical meanings from contexts through available pictures and objects and the structure of words. This might be that students may feel easy in using an English-Vietnamese dictionary. On the other hand, using a monolingual dictionary and guessing the meaning of unknown words can be time-consuming. However, these strategies can be very useful for language learners as using a monolingual dictionary and guessing lexical meanings in the context provide students chances to discover and construct lexical meanings by themselves, which can be effective in English examinations or tests when students are not allowed to use dictionaries and references (Luu, 2001).

Participants reported they sometimes employed Social strategies to learn lexicons. They tended to know lexical meanings from their teachers or classmates. This seems to be one of the fastest ways for them to know the lexical meanings as they may believe that their teachers and friends can be reliable sources. This finding is in alignment with that of Schmitt's (1997) study. On the contrary, participants did not interact with foreigners for meaning construction. This can be due to students' lack of confidence in communication.

Nevertheless, participants employed memory strategies the least. This can be due to participants' unfamiliarity with such strategies. Regarding cognitive strategies which were sometimes used in lexical learning. Participants preferred learning lexicons by highlighting them rather than writing lexicons on the boards or stickers or taking notes in class. This can be that participants may find the contexts helpful to recall the meanings of new words. Additionally, participants sometimes utilized metacognitive strategies. They enjoyed learning lexicons through English songs most, while they tended to learn lexicons from watching English programs, listening to English radio, or reading English news online less. One of the facts to explain this finding is that participants are young, and they may prefer something enjoyable and relaxing.

Another major finding is that participants' use of autonomous English LLS was significantly affected by gender. In other words, female students employed autonomous English LLS significantly more frequently than their male counterparts. The plausible explanation for this can be that technical male students may not prefer English to other subjects in comparison to their female peers. Other reasons may be due to differences in the characteristics of females and male's brains. According to Zaidi (2010), the female's brain can store language and organizing things better than the male's one. The second explanation is that females are reported to learn languages better than males Hall (2011). What is more, participants are technical students, so male students may tend to focus more on other subjects than English. This finding confirms that of Habibi and Samaie (2015).

\section{Conclusion}

Some conclusions can be made. Research participants in this study employed strategies for English lexical learning autonomously at a low frequency and female participants utilized such strategies more autonomously than their male fellows.

Some pedagogical implications are suggested in this study. First and foremost, teachers should provide their students with autonomous English LLS so that students can be aware of LLS and employ them in their learning autonomously. Then, teachers should monitor and check what their students can do and cannot do in terms of using autonomous English LLS, so they can assist their students to adjust their autonomous English lexical learning behaviors. Besides, teachers 
should give students activities to practice their autonomous English LLS so that students can find what LLS can fit their learning style most. Besides, teachers should instruct their students to select appropriate strategies that fit their learning styles. What is more, students, particularly male students, should be motivated and encouraged to learn vocabulary independently by learning incentives although they are technical students. Moreover, students should know how to monitor their lexical learning and assess it regularly.

This study still shows some limitations. Firstly, the questionnaire and semi-structured interviews were the main data sources, so participants may not have provided full and substantial information. Secondly, although 200 respondents were purposively sampled for questionnaires, only ten participants were invited for interviews. The findings could have been more comprehensive and generalized if there would have had more participants involving in the interviews.

\section{References}

Benson, P. (2001). Teaching and researching autonomy in language learning. London, UK: Longman.

Besthia, W. (2018). A survey on vocabulary learning strategies: A case of Indonesian EFL university students. Journal of Research \& Method in Education, 8(5), 636-641.

Cotterall, S. (2000). Promoting learner autonomy through the curriculum: Principles for designing language courses. English Language Teaching Journal, 54(2), 109-117. doi:10.1093/elt/54.2.109

Duong, T. M. (2014). EFL Teachers' perceptions of learner autonomy and their classroom practices: A case study. International Journal of Education and Management Engineering , 4(2), 9-17. doi:10.5815/ijeme.2014.02.02

Duong, T. M., \& Seepho, S. (2013). EFL teachers' perceptions of promoting learner autonomy in a Thai EFL context. Paper presented at CULI's International seminar 2013, Bangkok, Thailand.

Gremmo, M. J., \& Riley, P. (1995). Autonomy, self-direction and self-access in language teaching and learning: The history of an idea. System, 23(2), 151-164. doi:10.1016/0346251X(95)00002-2

Gu, Y. Q., \& Johnson, R. K. (1996). Vocabulary learning strategies and language learning outcomes. Language Learning, 46, 643-679. doi:10.1111/j.1467-1770.1996.tb01355.x

Hall, G. (2011). Exploring English language teaching language in action. New York, NY: Routledge Hall.

Intaraprasert, C. (2005). A preliminary investigation of vocabulary learning strategies employed by EST students. Suranaree Journal of Science and Technology, 12(2), 163-171.

Khalifa, S. H. A., \& Shabdin, A. A. (2016). Autonomy in vocabulary learning: Vocabulary learning strategies teaching programme for EFL Libyan learners. Arab World English Journal, 7(1), 140-159. doi:10.24093/awej/vol7no1.10

Le, H. P. H. (2018). A survey study on academic vocabulary learning strategies by EFL university students. Journal of Language Teaching and Research, 9(5), 1009-1016. doi:10.17507/jltr.0905.15 
Luu, T. T. (2001). An empirical research on self-learning vocabulary. Theory and Practice in Language Studies, 1(2), 1688-1695. doi:10.4304/tpls.1.12.1688-1695

McCarthy, M. (1992). Review of vocabulary. ELT Journal, 46(2), 228-229.

Nation, P. (2001). Learning vocabulary in another language. New York, NY: Cambridge University Press.

Naveh, M. H., Kafipour, R., \& Soltani, R. (2011). The relationship among extroversion tendency, vocabulary learning strategies and reading comprehension of EFL undergraduates in Kerman Province. Studies in Literature and Language, 3(2), 104-110.

Nguyen, T. N. (2013). The effects of semantic mapping on vocabulary memorizing. In Proceedings of the 3rd International Conference on Foreign Language Learning and Teaching (pp. 628-659). Bangkok, Thailand: The Language Institute, Thammasat University.

O’Malley, J. M., \& Chamot, A. U. (1990). Learning strategies in second language acquisition. Cambridge, UK: Cambridge University Press.

Pham, L. T. P. (2010). An examination of vocabulary learning strategies of first year students in USSH - VNUH (Master's thesis, Vietnam National University, Hanoi). Retrieved October 20, 2019, from https://repository.vnu.edu.vn/handle/VNU_123/40843

Richards, J. C., \& Renandya, W. A. (2002). Methodology in language teaching: An anthology of current practice. Cambridge, UK: Cambridge University Press.

Samaie, M., Habidi, N., \& Khany, R. (2015). On the relationship between learner autonomy and language learning strategies among Iranian EFL students. International Journal of Educational Investigations, 2(6), 96-109.

Schmitt, N. (1997). Vocabulary learning strategies. In D. N. Schmitt \& M. McCarthy (Eds.), Vocabulary: Description, acquisition and pedagogy (pp. 199-227). Cambridge, UK: Cambridge University Press.

Schmitt, N. (2010). Researching vocabulary: A vocabulary research manual. Basingstoke, UK: Palgrave Macmillan.

Sedighi, E., \& Tamjid, N. H. (2016). The relationship between Iranian EFL learners' autonomy and their vocabulary learning strategies with a focus on gender. The Journal of Applied Linguistics, 9(18), 183-196.

Tran, T. Q., \& Duong, T. M. (2018). EFL learners' perceptions of factors influencing learner autonomy development. Kasetsart Journal of Social Sciences, 39(1), 1-6. doi:10.1016/j.kjss.2018.02.009

Tran, T. Q., \& Nguyen, L. C. H. (2020). The use of self-regulated language learning strategies among Vietnamese English-majored freshmen: A case study. VNU Journal of Science: Education Research, 36(1), 1-10. doi:10.25073/2588-1159/vnuer.4331

Tran. T. Q., \& Nguyen, T. G. (2017). The use of English vocabulary learning strategies among Vietnamese high school students. In Proceedings of the Third International TESOL Conference Promoting ELT: Diverse Perspectives and New Horizons at Ho Chi Minh City University of Education (pp. 223-232). Ho Chi Minh City, Vietnam: Ho Chi Minh City University of Education Publishing House. 
Tran. T. Q., \& Vo. D. Q. (2019). Tertiary English majors' perceptions of the importance of learner autonomy and autonomous language learning strategy use. In Proceedings of the International Conference: Autonomy and Motivation for Language Learning in the Interconnected World at Ho Chi Minh City University of Technology and Education (pp. 102-113). Ho Chi Minh City, Vietnam: Vietnam National University - Ho Chi Minh Press.

Trinh, N. T. M., \& Trinh, N. B. (2019). A study on vocabulary learning strategies employed by the third-year English majored students at Tra Vinh University. Scientific Journal of Tra Vinh University, 1(35), 28-34. doi:10.35382/18594816.1.35.2019.200

Zaidi, Z. F. (2010). Gender differences in human brain: A review. The Open Autonomy Journal, 2, 37-55. doi:10.2174/1877609401002010037 